\title{
Efficient biosynthesis of cinnamyl alcohol by engineered Escherichia coli overexpressing carboxylic acid reductase in a biphasic system
}

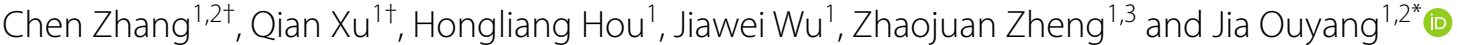

\begin{abstract}
Background: Cinnamyl alcohol is not only a kind of flavoring agent and fragrance, but also a versatile chemical applied in the production of various compounds. At present, the preparation of cinnamyl alcohol depends on plant extraction and chemical synthesis, which have several drawbacks, including limited scalability, productivity and environmental impact. It is therefore necessary to develop an efficient, green and sustainable biosynthesis method.

Results: Herein, we constructed a recombinant Escherichia coli BLCS coexpressing carboxylic acid reductase from Nocardia iowensis and phosphopantetheine transferase from Bacillus subtilis. The strain could convert cinnamic acid into cinnamyl alcohol without overexpressing alcohol dehydrogenase or aldo-keto reductase. Severe product inhibition was found to be the key limiting factor for cinnamyl alcohol biosynthesis. Thus, a biphasic system was proposed to overcome the inhibition of cinnamyl alcohol via in situ product removal. With the use of a dibutyl phthalate/water biphasic system, not only was product inhibition removed, but also the simultaneous separation and concentration of cinnamyl alcohol was achieved. Up to $17.4 \mathrm{mM}$ cinnamic acid in the aqueous phase was totally reduced to cinnamyl alcohol with a yield of $88.2 \%$, and the synthesized cinnamyl alcohol was concentrated to $37.4 \mathrm{mM}$ in the organic phase. This process also demonstrated robust performance when it was integrated with the production of cinnamic acid from L-phenylalanine.
\end{abstract}

Conclusion: We developed an efficient one-pot two-step biosynthesis system for cinnamyl alcohol production, which opens up possibilities for the practical biosynthesis of natural cinnamyl alcohol at an industrial scale.

Keywords: Cinnamyl alcohol, Product inhibition, Biphasic system, Carboxylic acid reductase

\section{Introduction}

Recently, due to the rapid depletion of fossil fuels and the increasing demand for aromatic compounds, the production of these compounds from plant resources has increased in interest [1]. Monolignols, which are units of plant lignin, are important aromatic compounds that can

*Correspondence: hgouyj@njfu.edu.cn

${ }^{\dagger}$ Chen Zhang and Qian Xu contributed equally to this work 1 Jiangsu Co-Innovation Center of Efficient Processing and Utilization of Forest Resources, College of Chemical Engineering, Nanjing Forestry University, Nanjing 210037, People's Republic of China

Full list of author information is available at the end of the article be used to generate a wide range of high-value chemicals of commercial interest [2]. They have received much attention with the development of market requirements [3-6]. However, most natural monolignols are found in low concentrations in plants, and their extraction is limited by plant growth and expensive downstream processing costs. Industrial biosynthesis offers a promising alternative as it allows for scalable production of natural monolignols from bioresources [7].

Cinnamyl alcohol, a natural aromatic alcohol, is the skeleton of monolignols. Cinnamyl alcohol not only is used in the food and cosmetic industries due to its sweetspicy odor and cinnamon taste, but also demonstrates 
good anti-inflammatory and antimicrobial activities [8-10]. In addition, cinnamyl alcohol is also a versatile chemical applied in the synthesis of various valuable compounds, such as cinnamyl esters (which are flavor and fragrance agents), flunarizine (which is used for fungal infection treatment), Taxol (which is a cancer treatment drug) and cinnamyl glycosides (which enhance immune function) [11-14]. Cinnamyl alcohol is also synthesized via the monolignol pathway in plants and the biotechnological production of natural cinnamyl alcohol has been reported by introducing the plant monolignol pathway into microbial strains [15]. As shown in Additional file 1: Figure S1, four enzymes involves in the synthesis of cinnamyl alcohol from L-phenylalanine in this pathway, including phenylalanine ammonia-lyase (PAL, EC 4.3.1.5), 4-coumarate: CoA ligase (4CL, EC 6.2.1.12), cinnamoyl-CoA reductase (CCR, EC 1.1.1.44) and cinnamyl alcohol dehydrogenase (CAD, EC 1.1.1.195) [16]. PAL catalyzes the conversion of L-phenylalanine to cinnamic acid, and 4CL catalyzes the subsequent conversion of cinnamic acid into CoA ester, which is reduced by CCR and CAD to cinnamyl alcohol. Zhou et al. constructed the pathway in Escherichia coli by overexpressing PAL, 4CL and CCR from different plant species. They found that endogenous alcohol dehydrogenases (ADHs) and aldo-keto reductases (AKRs) in E. coli could catalyze the reduction of cinnamaldehyde to cinnamyl alcohol, and the production of cinnamyl alcohol reached $2.13 \mathrm{mM}$ [14]. Our group reported that a higher concentration of cinnamyl alcohol $(4.8 \mathrm{mM})$ could be obtained using whole-cell biotransformation by introducing the pathway from Populus trichocarpa into E. coli BL21 (DE3) [17]. However, the current production of cinnamyl alcohol using this strategy is still unsatisfactory, as most characterized 4CLs demonstrated low activity towards cinnamic acid. Thus, a novel artificial approach mimicking the pathway of microbes (Additional file 1: Figure S1) was designed and a recombinant Saccharomyces cerevisiae strain coexpressing PAL2 from Arabidopsis thaliana (AtPAL2), carboxylic acid reductase from Nocardia otitidiscaviarum (NoCAR), and phosphopantetheine transferase from E. coli (EcSFP) was engineered for the bioconversion of L-phenylalanine to cinnamyl alcohol [2]. When endogenous reductases in S. cerevisiae were used, cinnamyl alcohol reached a maximum concentration of $0.83 \mathrm{mM}$ when $1.35 \mathrm{mM}$ cinnamic acid was added to the media. Klumbys et al. established a three-step cascade using PAL, CAR and ADH to synthesize approximately $4.3 \mathrm{mM}$ cinnamyl alcohol from $5 \mathrm{mM}$ L-phenylalanine after $27.5 \mathrm{~h}$ [18]. These findings suggested that biosynthesis of cinnamyl alcohol via the CAR pathway from microbes is potentially feasible and could avoid the problems associated with 4CL. However, reducing cinnamic acid to cinnamyl alcohol is still the limiting module in the cinnamyl alcohol biosynthesis pathway. To our knowledge, an enhanced biosynthesis strategy to overcome product inhibition has not been explored. There are no reports about the reduction of cinnamic acid to cinnamyl alcohol using heterologous CAR and endogenous ADHs or AKRs in E. coli.

Here, we report a new, high-yielding biphasic biotransformation for the one-pot two-step biosynthesis of cinnamyl alcohol from cinnamic acid. The recombinant E. coli strain BLCS, coexpressing CAR from Nocardia iowensis (NiCAR) and SFP from Bacillus subtilis (BSSFP), catalyzed the one-step reduction of cinnamic acid to cinnamic aldehyde. Cinnamaldehyde was then converted to cinnamyl alcohol by endogenous ADHs and AKRs. Subsequently, cinnamyl alcohol was indicated to cause severe product inhibition on its biosynthesis and a biphasic system was used to overcome this problem via in situ product removal for the first time.

\section{Materials and methods \\ Materials}

Isopropyl- $\beta$-D-1-thiogalactopyranoside (IPTG) and ampicillin were purchased from Sangon (Shanghai, China). Tryptone and yeast extract were purchased from Oxoid Co. Ltd. (Basingstoke, United Kingdom). Cinnamic acid and L-phenylalanine were purchased from Sigma-Aldrich (Shanghai, China). All other chemical reagents were of analytical grade and were commercially available.

\section{Plasmids, bacterial strains, and culture conditions}

The plasmid and bacterial strains used in this study are listed in Additional file 1: Table S1. The E. coli BL21 (DE3) and recombinant strains used for gene cloning and biotransformation were cultivated in Luria-Bertani (LB) broth media supplemented with streptomycin or ampicillin at $200 \mathrm{rpm}$ and $37^{\circ} \mathrm{C}$.

\section{Construction of recombinant strains}

All DNA manipulation and general molecular biology techniques were conducted according to standard protocols. The NiCAR (GenBank number: Q6RKB1.1), MpCAR (CAR from Mycobacterium phlei, GenBank number: WP_003889896.1), NoCAR (GenBank number: WP_029928026.1) and BSSFP (GenBank number: WP_003234549.1) genes were codon-optimized and synthesized using a synthetic DNA service provider (General Biotechnology Co, Ltd., Chuzhou, China). Each $C A R$ gene was inserted into the Nco I-BamH I sites of a pCDFDuet-1 (multiple cloning site I, MCS I) vector to generate corresponding pCDFDuet-CARs. Thereafter, $B s S F P$ was inserted into the $B g l$ II-Kpn I sites of MCS II 
of the pCDFDuet-CAR vector to generate pCDFDuetNiCAR-BsSFP, pCDFDuet-NoCAR-BsSFP and pCDFDuet-MpCAR-BsSFP plasmids, which were subsequently introduced into E. coli BL21 (DE3), generating the corresponding recombinant strains $E$. coli BLCS, E. coli BLCS$\mathrm{N}$ and E. coli BLCS-M.

\section{Biotransformation of cinnamic acid to cinnamyl alcohol by whole-cell catalysts in a monophasic or biphasic system} The recombinant $E$. coli cells were cultivated, washed and suspended in $100 \mathrm{mM}$ sodium phosphate buffer ( $\mathrm{pH} 7.5)$ for further study. The biotransformation reactions were performed in $50 \mathrm{~mL}$ flasks that contained $3 \mathrm{~mL}$ of a reaction mixture consisting of $100 \mathrm{mM}$ sodium phosphate buffer (pH 7.5), E. coli cells, cinnamic acid and glucose. The comparison of the cinnamyl alcohol synthesis ability of different strains was performed under the following conditions for $4 \mathrm{~h}$ : $11 \mathrm{mM}$ cinnamic acid, $55 \mathrm{mM}$ glucose and different wet cells at an optical density of $50\left(\mathrm{OD}_{600 \mathrm{~nm}}\right.$ 50 ) in the reaction mixtures, $42{ }^{\circ} \mathrm{C}$, and $200 \mathrm{rpm}$. To investigate substrate inhibition, reaction mixtures consisting of 5.7-18 $\mathrm{mM}$ cinnamic acid, $55 \mathrm{mM}$ glucose and wet cells at an optical density of $50\left(\mathrm{OD}_{600 \mathrm{~nm}} 50\right)$ were used. Biotransformation was performed at $42{ }^{\circ} \mathrm{C}$ with rotary shaking at $200 \mathrm{rpm}$ for $2 \mathrm{~h}$. To investigate production inhibition, reaction mixtures consisting of $8.5 \mathrm{mM}$ cinnamic acid, $51 \mathrm{mM}$ glucose, 0-5.5 mM cinnamic alcohol and wet cells at an optical density of $50\left(\mathrm{OD}_{600 \mathrm{~nm}}\right.$ 50) were prepared. Biotransformation was carried out at $30{ }^{\circ} \mathrm{C}$ with rotary shaking at $200 \mathrm{rpm}$ for $2 \mathrm{~h}$. The samples were heated to $100{ }^{\circ} \mathrm{C}$ and then centrifuged at $10,000 \mathrm{~g}$ for $10 \mathrm{~min}$. The concentrations of cinnamic acid, cinnamyl alcohol, cinnamaldehyde and 3-phenylpropanol in the supernatants were quantitatively analyzed by high-performance liquid chromatography (HPLC).

To explore the effects of organic solvent on the distribution coefficients, $3 \mathrm{~mL}$ of dibutyl phthalate, $n$-octane, $n$-hexane, $n$-octanol, ethyl acetate and $n$-hexanol was added to $3 \mathrm{~mL}$ of $100 \mathrm{mM}$ PBS (pH 7.5) that included $18 \mathrm{mg}$ of cinnamic acid, cinnamyl alcohol and cinnamaldehyde. The experiment was carried out at $30{ }^{\circ} \mathrm{C}$ with rotary shaking at $200 \mathrm{rpm}$, and samples were taken from different phases after $2 \mathrm{~h}$.

The experiments to measure the effects of the phase ratio on the biosynthesis of cinnamyl alcohol were carried out as follows: wet cells at an optical density of 50 $\left(\mathrm{OD}_{600 \mathrm{~nm}} 50\right)$ suspended in $3 \mathrm{~mL}$ of PBS (100 mM, pH 7.0) including $17.4 \mathrm{mM}$ cinnamic acid (based on the aqueous phase), $102 \mathrm{mM}$ glucose and wet cells at an optical density of $50\left(\mathrm{OD}_{600 \mathrm{~nm}} 50\right)$ and different volumes $(0 \mathrm{~mL}, 0.6 \mathrm{~mL}, 1.2 \mathrm{~mL}, 1.8 \mathrm{~mL}, 2.4 \mathrm{~mL}$, and $3 \mathrm{~mL}$ ) of dibutyl phthalate were mixed together and incubated at $30{ }^{\circ} \mathrm{C}$ and $200 \mathrm{rpm}$ for $6 \mathrm{~h}$. The effects of substrate concentration (8.8-32 $\mathrm{mM}$, based on the aqueous phase) were investigated on the basis of the optimized organic phase ratio. Samples were taken from different phases.

$V_{0}(\mathrm{mM} / \mathrm{h})$ was defined as the increase in concentration of cinnamyl alcohol during the initial reaction stage $(1 \mathrm{~h})$. The conversion and yield were calculated using the following equations:

$$
\begin{aligned}
& \text { Conversion }(\%)=\left(\mathrm{Ns}_{1}-\mathrm{Ns}_{2}\right) / \mathrm{N}_{\mathrm{S} 1} \times 100 \% \\
& \text { Yield }(\%)=\mathrm{N}_{\mathrm{P}} / \mathrm{Ns}_{1} \times 100 \%
\end{aligned}
$$

$\mathrm{N}_{\mathrm{S} 1}$ is the initial moles of the substrate (mol), $\mathrm{N}_{\mathrm{S} 2}$ is the total moles of the substrate at equilibrium (mol), and $\mathrm{N}_{\mathrm{P}}$ is the total moles of the product (mol) at equilibrium.

\section{Biosynthesis of cinnamyl alcohol from L-phenylalanine} Whole-cell catalysis of the transformation of L-phenylalanine to cinnamic acid was performed in $50 \mathrm{~mL}$ flasks that contained $3 \mathrm{~mL}$ of a reaction mixture consisting of $100 \mathrm{mM}$ Tris- $\mathrm{HCl}$ buffer ( $\mathrm{pH}$ 8.5), E. coli BLP3 $\left(\mathrm{OD}_{600 \mathrm{~nm}}\right.$ $15)$, and $40 \mathrm{mM} \mathrm{L}$-phenylalanine. The reaction was performed at $55{ }^{\circ} \mathrm{C}$ with rotary shaking at $200 \mathrm{rpm}$ for $2 \mathrm{~h}$. Afterward, the mixture was heated to $100{ }^{\circ} \mathrm{C}$ and then centrifuged at $10,000 \mathrm{~g}$ for $3 \mathrm{~min}$. Subsequently, $102 \mathrm{mM}$ glucose and a certain amount of cells $\left(\mathrm{OD}_{600 \mathrm{~nm}} 50\right)$ were added to $1.5 \mathrm{~mL}$ of the supernatant and $1.5 \mathrm{~mL}$ of $200 \mathrm{mM}$ PBS (consisting of $204 \mathrm{mM}$ glucose and E. coli BLCS cells at $\left.\mathrm{OD}_{600 \mathrm{~nm}} 100\right)$ were mixed together. The second reaction was started after the addition of $1.2 \mathrm{~mL}$ of dibutyl phthalate and was carried out at $30{ }^{\circ} \mathrm{C}$ and $200 \mathrm{rpm}$ for $6 \mathrm{~h}$.

\section{Analytical methods}

HPLC analysis was carried out on an Agilent 1260 Series instrument together with an Eclipse XDB-C18 column $(250 \mathrm{~mm} \times 4.6 \mathrm{~mm}, 5 \mu \mathrm{m})$. The concentrations of cinnamyl alcohol, cinnamic acid, cinnamaldehyde, and 3-phenylpropanol were monitored by measuring the absorbance at $254 \mathrm{~nm}$. The mobile phase consisted of acetonitrile (A), methanol (B) and $25 \mathrm{mM}$ potassium phosphate buffer ( $\mathrm{pH} 2.5)$ (C), and an elution gradient elution was used: the ratio of the mobile phase was changed from $1: 2: 7(\mathrm{~A}: \mathrm{B}: \mathrm{C})$ to $2: 1: 7$, and the flow rate was increased from $0.8 \mathrm{~mL} / \mathrm{min}$ to $0.9 \mathrm{~mL} / \mathrm{min}$ for $5 \mathrm{~min}$. After maintaining the ratio for $10 \mathrm{~min}$, the ratio was changed back to $1: 2: 7$, and the flow rate was decreased to $0.8 \mathrm{~mL} / \mathrm{min}$ for $1 \mathrm{~min}$. These parameters were maintained for $3 \mathrm{~min}$ after which the flow rate was decreased to $0.4 \mathrm{~mL} / \mathrm{min}$ for $3 \mathrm{~min}$. The flow rate was then increased and increasing to $0.8 \mathrm{~mL} / \mathrm{min}$ for $8 \mathrm{~min}$, which was then maintained for $10 \mathrm{~min}$. The column temperature was set to $40{ }^{\circ} \mathrm{C}$. 


\section{Statistical analysis}

Statistical analyses were performed using SPSS 25.0. The differences in the corresponding values between the groups were tested by one-way analysis of variance (ANOVA). $p<0.05$ was considered statistically significant.

\section{Results and discussion}

Biosynthesis of cinnamyl alcohol from cinnamic acid by $E$. coli BLCS in the monophasic aqueous system

Since the discovery of CAR in 1997, researchers have conducted many studies involving this enzyme [19]. CAR is a kind of enzyme with broad substrate specificity, and a variety of CARs exhibit cinnamic acid catalytic activity [20]. BsSFP can facilitate posttranslational modification of CAR and improve its activity [19, 21-25]. First, we screened MpCAR, NoCAR, and NiCAR, which have good cinnamic acid activity and coexpressed them in E. coli with BsSFP. To compare their ability to synthesize cinnamyl alcohol, the three strains were fed with $11.0 \mathrm{mM}$ cinnamic acid. In addition, glucose was added as a cosubstrate to provide indispensable cofactors including NADH, NADPH and ATP. As shown in Fig. 1, the E. coli BLCS strain containing the pCDFDuetNiCAR-BsSFP plasmid synthesized $5.5 \mathrm{mM}$ cinnamyl alcohol, which was $44.6 \%$ and $6.2 \%$ higher than E. coli BLCS-M and E. coli BLCS-N, respectively. In addition, the concentrations of residual cinnamic acid, cinnamaldehyde and by-product 3-phenylpropanol were low. Thus, we focused on whole-cell biotransformation by $E$. coli BLCS.

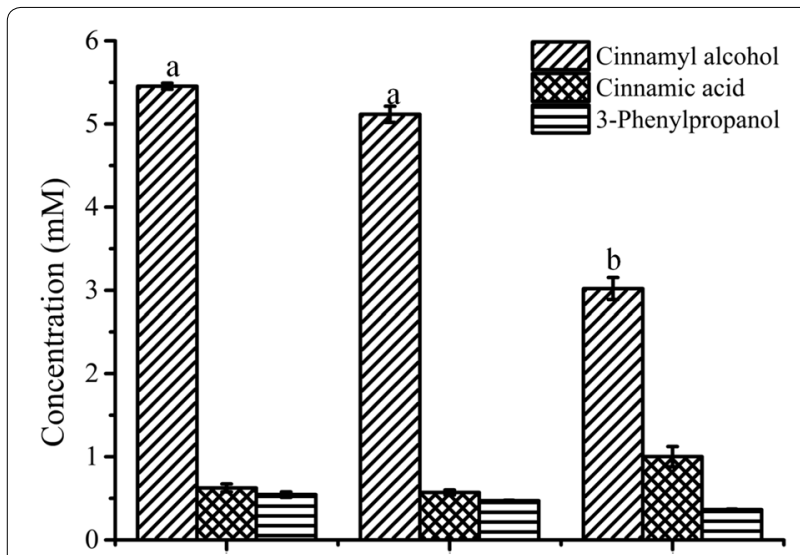

E. coli BLCS E. coli BLCS-N E. coli BLCS-M

Fig. 1 Comparison of the ability of different strains to synthesize cinnamyl alcohol. Conditions: $11 \mathrm{mM}$ cinnamic acid, $55 \mathrm{mM}$ glucose, different wet cells $\left(\mathrm{OD}_{600 \mathrm{~nm}} 50\right), 100 \mathrm{mM}$ phosphate buffer $(\mathrm{pH} 7.5)$, $200 \mathrm{rpm}, 42^{\circ} \mathrm{C}, 3 \mathrm{~mL}$ final volume; the reaction lasted $4 \mathrm{~h}$ under the above conditions, with the different letters representing significant differences between the treatment means $(p<0.05)$
Limiting factors of the biosynthesis of cinnamyl alcohol by $E$. coli BLCS in the monophasic aqueous system

The effects of cinnamic acid on cinnamyl alcohol biosynthesis were studied. As shown in Fig. 2, the initial concentration of cinnamic acid exerted no significant effect on the conversion when cinnamic acid concentrations were lower than $8.6 \mathrm{mM}$. However, when the cinnamic acid concentration was greater than $8.6 \mathrm{mM}$, the conversion began to decrease obviously. In addition, $V_{0}$ was $4.83 \mathrm{mM} / \mathrm{h}$ at the initial $8.6 \mathrm{mM}$ cinnamic acid and it decreased by $22.6 \%$ when the substrate concentration reached $18 \mathrm{mM}$. The substrate was completely converted within $2 \mathrm{~h}$, and the highest concentration of cinnamyl alcohol $(6.37 \mathrm{mM})$ was obtained with a yield of $75.7 \%$ when the initial concentration of cinnamic acid was $8.6 \mathrm{mM}$. These results implied that substrate inhibition was obvious when the cinnamic acid concentration exceeded $8.6 \mathrm{mM}$, which was an obstacle to the production of cinnamyl alcohol.

The enzymes in this pathway may be temperature and $\mathrm{pH}$ dependent. By using a substrate concentration of $8.6 \mathrm{mM}$, we investigated the effects of temperature and $\mathrm{pH}$ on whole-cell catalysis. Additional file 1: Figure S3 shows that temperatures between 30 and $42{ }^{\circ} \mathrm{C}$ resulted in similar cinnamic acid conversions, and the optimum temperature for the synthesis of cinnamyl alcohol was $30{ }^{\circ} \mathrm{C}$. As shown in Additional file 1: Figure S4, E. coli BLCS cells exhibited good catalytic performance within the $\mathrm{pH}$ range of 7.0-8.0. In addition, the conversions of cinnamic acid were $100 \%$, and the yield of cinnamyl alcohol reached $7.37 \mathrm{mM}$. We further studied the effects of cell dosage and the molecular ratio of substrate to cosubstrate on the biosynthesis of cinnamyl alcohol to optimize

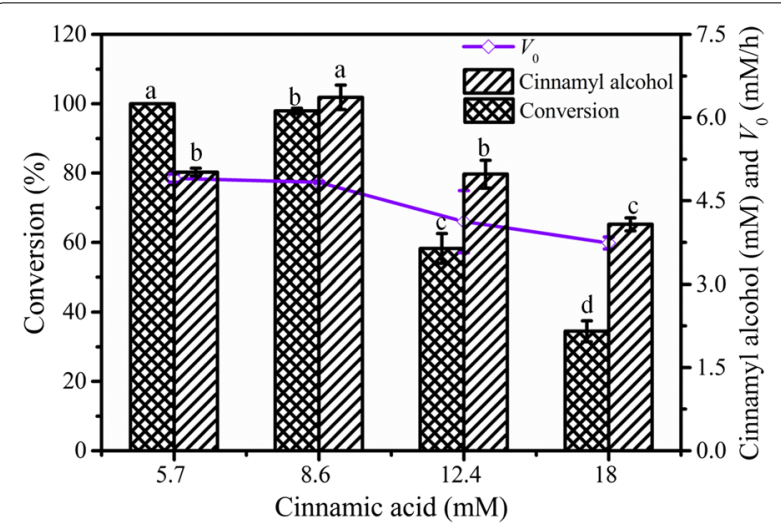

Fig. 2 Effects of initial cinnamic acid concentration on whole-cell biotransformation. Conditions: 5.7-18 mM cinnamic acid, $55 \mathrm{mM}$ glucose, wet cells $\left(\mathrm{OD}_{600 \mathrm{~nm}} 50\right), 100 \mathrm{mM}$ phosphate buffer ( $\left.\mathrm{pH} 7.5\right)$, $200 \mathrm{rpm}, 42^{\circ} \mathrm{C}, 3 \mathrm{~mL}$ final volume; the reaction lasted $2 \mathrm{~h}$ under the above conditions, with the different letters representing significant differences between the treatment means $(p<0.05)$ 
catalytic conditions. As shown in Additional file 1: Figures $\mathrm{S} 5$, S6, the optimum cell dosage was $\mathrm{OD}_{600 \mathrm{~nm}} 50$, and the optimum molecular ratio of substrate to co-substrate was 1:6. Under the optimal conditions, the cinnamic acid was completely converted, and $7.51 \mathrm{mM}$ cinnamyl alcohol accumulated in $2 \mathrm{~h}$ with a yield of $92.8 \%$.

It is possible that the presence of product could have a negative effect on the conversion or yield. Thus, the effects of the product on the biocatalytic cascade were also analyzed by adding cinnamyl alcohol at the beginning of the reaction. As shown in Fig. 3, the initial cinnamyl alcohol concentrations obviously affected the conversion of cinnamic acid. When the initial concentration of cinnamyl alcohol was $5.5 \mathrm{mM}$, the conversion of cinnamic acid considerably decreased to $32.8 \%$. In addition, the $V_{0}$ was $4.65 \mathrm{mM} / \mathrm{h}$ without the addition of cinnamyl alcohol and it decreased substantially with the increase in the initial concentration of cinnamyl alcohol. When the initial concentration of cinnamyl alcohol

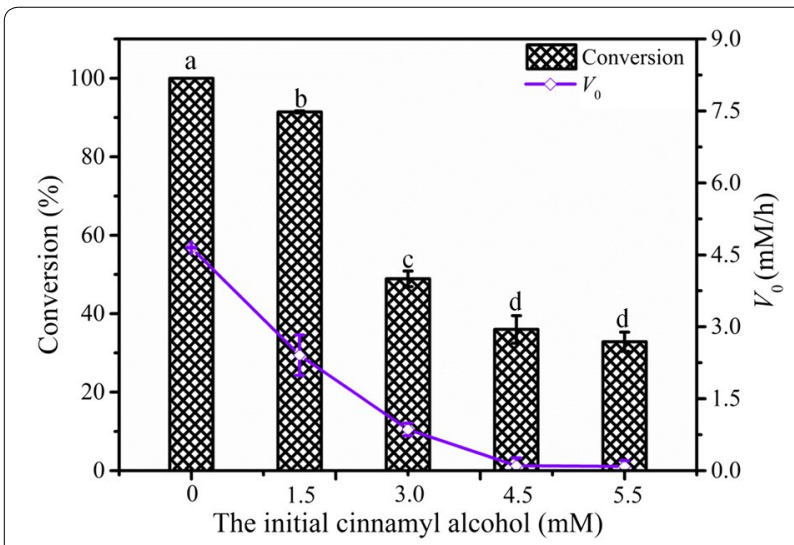

Fig. 3 Effects of initial cinnamyl alcohol concentration on whole-cell biotransformation. Conditions: 0-5.5 mM cinnamyl alcohol, $8.5 \mathrm{mM}$ cinnamic acid, $51 \mathrm{mM}$ glucose, wet cells $\left(\mathrm{OD}_{600 \mathrm{~nm}} 50\right), 100 \mathrm{mM}$ phosphate buffer ( $\mathrm{pH} 7.5), 200 \mathrm{rpm}, 30^{\circ} \mathrm{C}, 3 \mathrm{~mL}$ final volume; the reaction lasted $2 \mathrm{~h}$ under the above conditions, with different the letters representing significant differences between the treatment means $(p<0.05)$ reached $5.5 \mathrm{mM}$, the $V_{0}$ decreased by $90.2 \%$. This phenomenon indicated that cinnamyl alcohol results in strong feedback inhibition, which was even more severe than substrate inhibition. At present, there are no relevant reports showing that the product inhibition of cinnamyl alcohol is the main bottleneck for its biosynthesis.

\section{Selection of organic solvent for cinnamyl alcohol biosynthesis}

Several approaches have been used to address product or substrate inhibition, such as adding organic solvents to reduce their concentration in the aqueous phase or altering the structure of enzymes using site-directed mutagenesis [26-29]. A biphasic system was chosen to address the problem in this work.

We investigated the distribution of cinnamic acid and its downstream products in six organic solvents. As shown in Table 1, cinnamic acid exhibited extensive hydrophilicity in different organic solvents. Most of the cinnamic acid was distributed in the aqueous phase, which is beneficial for microbes to acquiring substrates. In addition, a portion of the cinnamic acid was dissolved in the organic phase and it would gradually enter the aqueous phase as its content in the aqueous phase decreased during biotransformation. Thus, this phenomenon may be conductive to relieving substrate inhibition. As the reduction product of cinnamic acid, cinnamaldehyde is cytotoxic to microorganisms [2]. It showed good lipophilicity in all six organic solvents, and dibutyl phthalate (with the highest $\log P$ value) demonstrated the strongest solubility for cinnamaldehyde. It was proposed that using dibutyl phthalate as an organic solvent may be beneficial for removing cinnamaldehyde in the water phase and for reducing its toxicity to microorganisms. However, whether this removal leads to a reduction in the end product still requires further experiments. Compared with cinnamic acid and cinnamaldehyde, the terminal product cinnamyl alcohol exhibited moderate lipophilicity in the organic solvents. With the exceptions of $n$-hexane and $n$-octane, the other four organic solvents, especially

Table 1 Distribution coefficients of cinnamic acid and its derivatives in different biphasic systems

\begin{tabular}{|c|c|c|c|c|}
\hline Organic solvent & $\log P^{a}$ & $\begin{array}{l}\log P \\
\text { cinnamic acid }\end{array}$ & $\begin{array}{l}\log P \\
\text { cinnamyl alcohol }\end{array}$ & $\begin{array}{l}\log P \\
\text { cinnamaldehyde }\end{array}$ \\
\hline Dibutyl phthalate & 5.4 & -0.65 & 1.55 & 3.19 \\
\hline n-Octane & 4.5 & -2.16 & 0.22 & 1.62 \\
\hline$n$-Hexane & 3.5 & -4.53 & -0.42 & 1.29 \\
\hline n-Octanol & 2.9 & -0.50 & 1.73 & 1.90 \\
\hline Ethyl acetate & 1.7 & -0.46 & 1.55 & 1.98 \\
\hline n-Hexanol & 1.4 & -0.36 & 1.98 & 2.73 \\
\hline
\end{tabular}

a Data from Laane et al. [30] 
$n$-octanol and $n$-hexanol, could effectively extract cinnamyl alcohol from the aqueous phase, suggesting that those solvents could be used to relieve the inhibition of cinnamyl alcohol for bioconversion.

With respect to biphasic biotransformation, organic solvents not only influence the distribution of compounds, but also are toxic to microorganisms and affect the activity of cells [31]. Thus, the four organic solvents and an equal volume of water phase (consisting of $17.4 \mathrm{mM}$ cinnamic acid) were mixed together to construct a biphasic system. The effects of the different organic solvents on the bioconversion were shown in Fig. 4. A yield of $57.8 \%$ and conversion of $65.6 \%$ were obtained using the monophasic system. With the use of a biphasic system, the other three organic solvents did not work well, indicating that they showed greater molecular toxicity to microbial cells and are not conducive to biotransformation. In the dibutyl phthalate-aqueous system, cinnamic acid was totally converted with a cinnamyl alcohol yield of $74.7 \%$. Moreover, only a small amount of cinnamyl alcohol was present in the aqueous phase (Additional file 1: Table S2). As expected, dibutyl phthalate maintained the cell activity at a relatively good level, and the dibutyl phthalate-aqueous system could not only promote biotransformation by removing product inhibition, but also realize the simultaneous synthesis and separation of cinnamyl alcohol. Hence, dibutyl phthalate was selected as a suitable organic phase of the biphasic system for the biotransformation of cinnamic acid to cinnamyl alcohol.

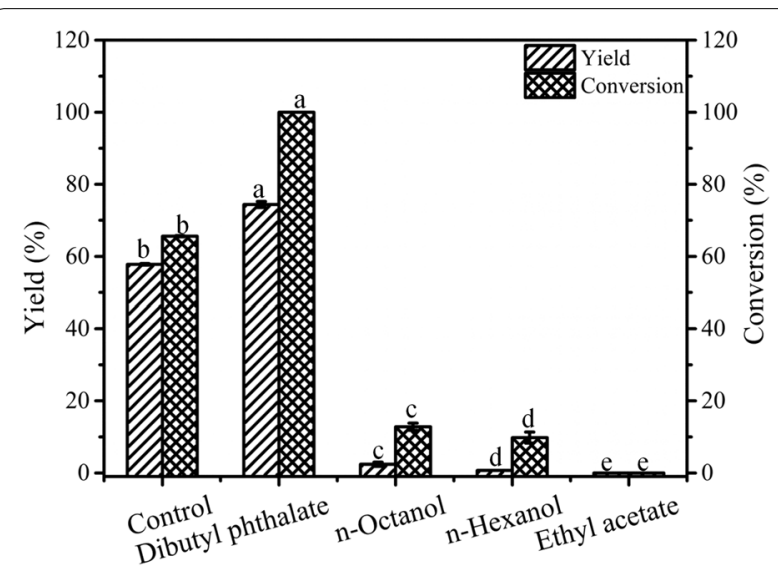

Fig. 4 Effects of various organic solvents on bioconversion by whole-cell catalysis in biphasic system. Conditions: $3 \mathrm{~mL}$ of $100 \mathrm{mM}$ phosphate buffer ( $\mathrm{pH} 7.5$ ) consisting of $17.4 \mathrm{mM}$ cinnamic acid, $102 \mathrm{mM}$ glucose, wet cells $\left(\mathrm{OD}_{600 \mathrm{~nm}} 50\right)$ and $3 \mathrm{~mL}$ of various organic solvents were mixed together at $200 \mathrm{rpm}$ and $30^{\circ} \mathrm{C}$ for $6 \mathrm{~h}$ under the above conditions, with different letters representing significant the differences between the treatment means $(p<0.05)$
Effects of the phase ratio on bioconversion in the biphasic system

In an organic-aqueous biphasic system, the volumetric phase ratio influences both the interfacial areas and cell viability [31-34]. These influences may affect microbial glucose metabolism, which indirectly affects the ability of cells to supply cofactors. Thus, the effects of the ratio of organic to aqueous phases on bioconversion were evaluated. As shown in Fig. 5b, once the organic phase was used, $17.4 \mathrm{mM}$ cinnamic acid could be completely transformed in $6 \mathrm{~h}$. The cinnamyl alcohol yield decreased slightly with the increase in the ratio of organic to aqueous phase $(\mathrm{v} / \mathrm{v})$, and higher yields were observed at the ratios of 0.4 and 0.6. Moreover, the ratio had a significant effect on the cinnamyl alcohol concentration in the organic phase, and it reached the maximum at the ratio of 0.4. As a result, the optimal ratio of the dibutyl phthalate phase to the aqueous phase was considered to be 0.4 . Under these conditions, the yield was $88.2 \%$, and cinnamyl alcohol in the organic phase reached $37.4 \mathrm{mM}$ (corresponding to $5.02 \mathrm{~g} / \mathrm{L}$ ). The highest reported level of cinnamyl alcohol biosynthesis was approximately $4.8 \mathrm{mM}$ [17] and it reached $10.99 \mathrm{mM}$ (based on the total system) in this study, which was $143.1 \%$ higher than previously reported values. Moreover, the system synchronized the reaction, separation and concentration (Fig. 5a); hence, we could directly obtain the product from the organic phase at the level of grams per liter, which was conducive to product purification. Therefore, subsequent experiments were performed in the dibutyl phthalate-aqueous system with a volume ratio of 0.4 .

\section{Effects of substrate concentrations on the production of cinnamyl alcohol in the biphasic system}

The effects of substrate concentration on bioconversion were further evaluated in the biphasic system. As shown in Table 2, increasing cinnamic acid concentration to $24.7 \mathrm{mM}$ still resulted in complete conversion (100\%). However, the yield of cinnamyl alcohol decreased obviously and the amount of cinnamaldehyde in the organic phase increased significantly with increasing substrate concentration. In this work, the biosynthesis of cinnamyl alcohol from cinnamic acid involved two steps: cinnamaldehyde production by the recombinant NiCAR and cinnamaldehyde bioreduction by endogenous ADHs and AKRs of E. coli. Thus the imbalance of activities between the recombinant $\mathrm{NiCAR}$ and endogenous reductases would result in the accumulation of cinnamaldehyde, but a low level of cinnamaldehyde in the monophasic system seemed to prevent this possibility. When the biphasic system is used, taking account of dibutyl phthalate's good ability to extraction cinnamaldehyde, it can be reasonably 

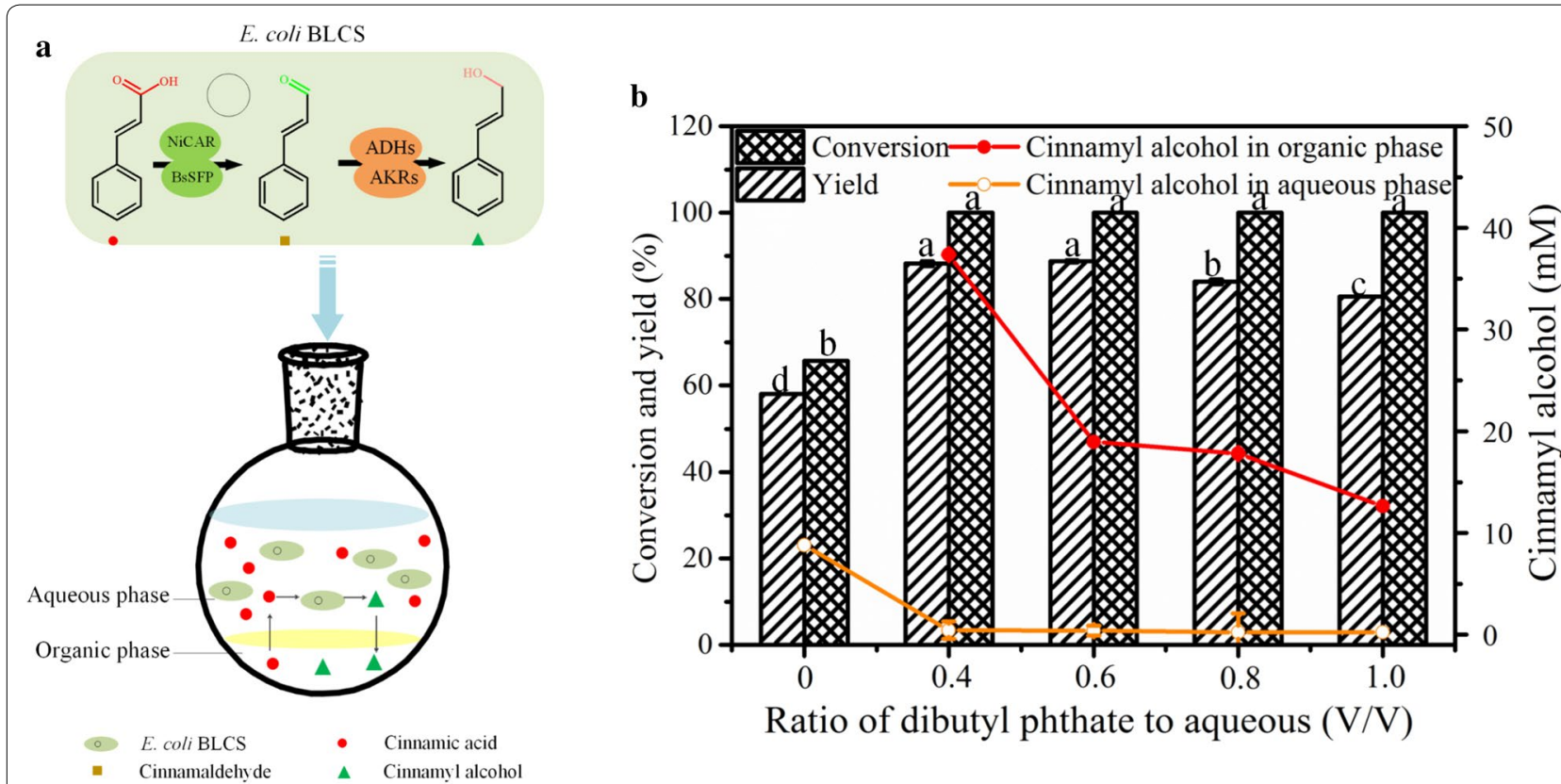

Fig. 5 Schematic of the whole-cell catalysis of cinnamic acid to cinnamyl alcohol by E. coli BLCS in a biphasic system (a). Effects of volumetric ratio of the organic phase to the aqueous phase on the biosynthesis of cinnamyl alcohol (b). Conditions: $3 \mathrm{~mL}$ of $100 \mathrm{mM}$ phosphate buffer (pH 7.5) consisting of $17.4 \mathrm{mM}$ cinnamic acid, $102 \mathrm{mM}$ glucose, wet cells $\left(\mathrm{OD}_{600 \mathrm{~nm}} 50\right)$ and $0-3 \mathrm{~mL}$ of dibutyl phthalate were mixed together at $200 \mathrm{rpm}$, $30^{\circ} \mathrm{C}$; the reaction lasted $6 \mathrm{~h}$ under the above conditions, with the different letters representing significant differences between the treatment means $(p<0.05)$

expected that the cinnamaldehyde produced after the 1st step has two outlets: one is to synthesize corresponding alcohol continually in microbes via the 2 nd step, and the other involves being released from the cells and entering into the organic phase. There is a competitive relation between the above two pathways. Once cinnamaldehyde entered into the organic phase, the 2 nd reaction did not occur because the cells could not effectively come into contact with cinnamaldehyde in dibutyl phthalate. In addition, cinnamaldehyde is cytotoxic and the intracellular accumulation of cinnamaldehyde has a negative effect on cell vitality, which in turn affects the biosynthesis of cinnamyl alcohol. Therefore, as the substrate concentration increased, an increasing amount of cinnamaldehyde was produced, which contributed to the distribution of cinnamaldehyde in the organic phase. It was supposed that this problem might be solved by overexpression of other $\mathrm{ADH}$ and AKR with higher activity.

\section{Biosynthesis of cinnamyl alcohol from L-phenylalanine} In terms of industrialization, the synthesis of cinnamyl alcohol from inexpensive substrates such as glucose is the direction headed. Considering that L-phenylalanine has been successfully produced from glucose by fermentation with high yields [35-38], we studied the biosynthesis of cinnamyl alcohol from L-phenylalanine. Previously, we found that recombinant E. coli BLP3 overexpressing PAL3 from $P$. trichocarpa (PtrPAL3) could synthesize cinnamic acid from L-phenylalanine efficiently by whole-cell biotransformation [39]. Therefore, we chose this strain to synthesize cinnamic acid, which was coupled with the synthesis of cinnamyl alcohol in the biphasic system. The coupled reaction was performed in a sequential manner. A full time course experiment of the two biocatalytic systems was performed, the results of which are shown in Fig. 6. L-Phenylalanine $(40 \mathrm{mM})$ was converted to cinnamic acid in $2 \mathrm{~h}$ by $E$. coli BLP3, with a conversion of $87.2 \%$. The supernatant $(1.5 \mathrm{~mL})$ was added to the aqueous phase (the volume increased to $3 \mathrm{~mL}$ ) to conduct the subsequent reaction by $E$. coli BLCS in the biphasic system for 6 h. Finally, $0.049 \mathrm{mmol}$ cinnamyl alcohol was synthesized from $0.06 \mathrm{mmol} \mathrm{L}$-phenylalanine with a yield of $81.7 \%$ after $8 \mathrm{~h}$. Moreover, the concentration of cinnamyl alcohol in the organic phase reached $38.23 \mathrm{mM}$ with a high purity of $92.9 \%$ (Additional file 1: Table S3). Klumbys et al. used a three-step cascade to convert L-phenylalanine to cinnamyl alcohol $(4.3 \mathrm{mM})$ in $27.5 \mathrm{~h}$ [13]. In contrast, the coupling process established in this study had higher cinnamyl alcohol synthesis efficiency, suggesting that the method may be applicable to the de novo biosynthesis of cinnamyl alcohol. 
Table 2 Effects of initial substrate concentration in the aqueous phase on the biosynthesis of cinnamyl alcohol in the biphasic system

\begin{tabular}{|c|c|c|c|c|c|c|}
\hline \multirow{2}{*}{$\begin{array}{l}\text { The initial substrate } \\
\text { in the aqueous phase } \\
\text { (mM) }\end{array}$} & \multicolumn{2}{|c|}{ Organic phase (mM) } & \multicolumn{2}{|c|}{ Aqueous phase (mM) } & \multirow[t]{2}{*}{ Yield (\%) } & \multirow[t]{2}{*}{ Conversion (\%) } \\
\hline & Cinnamyl alcohol & Cinnamaldehyde & Cinnamyl alcohol & Cinnamaldehyde & & \\
\hline 17.4 & $37.36 \pm 0.24$ & $4.34 \pm 0.19$ & $0.41 \pm 0.06$ & $0.13 \pm 0$ & $88.2 \pm 0.56$ & $100 \pm 0.05$ \\
\hline 24.7 & $34.13 \pm 0$ & $22.84 \pm 0$ & $0.52 \pm 0$ & $0.21 \pm 0$ & $59.0 \pm 0$ & $100 \pm 0.04$ \\
\hline 32.0 & $27.44 \pm 0$ & $31.40 \pm 0$ & $0.27 \pm 0$ & $0.22 \pm 0$ & $45.5 \pm 0$ & $77.2 \pm 0.03$ \\
\hline
\end{tabular}

Conditions: $3 \mathrm{~mL}$ of $100 \mathrm{mM}$ phosphate buffer (pH 7.5) consisting of $17.432 \mathrm{mM}$ cinnamic acid, $102 \mathrm{mM}$ glucose, wet cells ( $\left(\mathrm{OD}_{600 \mathrm{~nm}} 50\right)$ and $1.2 \mathrm{~mL}$ of dibutyl phthalate, $200 \mathrm{rpm}, 30^{\circ} \mathrm{C}$; the reaction lasted $6 \mathrm{~h}$ under the above conditions

\section{Conclusion}

Herein, we focused on the key module of the cinnamyl alcohol biosynthesis pathway, reducing cinnamic acid to cinnamyl alcohol. An efficient biotransformation approach was successfully established using recombinant E. coli BLCS coexpressing NiCAR and BsSFP in this work.
A biphasic system was indicated to be an effective strategy for improving the catalytic performance of microbial cells. The use of dibutyl phthalate successfully removed cinnamyl alcohol from the aqueous phase, thus avoiding severe product inhibition and realizing the concentration of cinnamyl alcohol simultaneously. Up to $17.4 \mathrm{mM}$

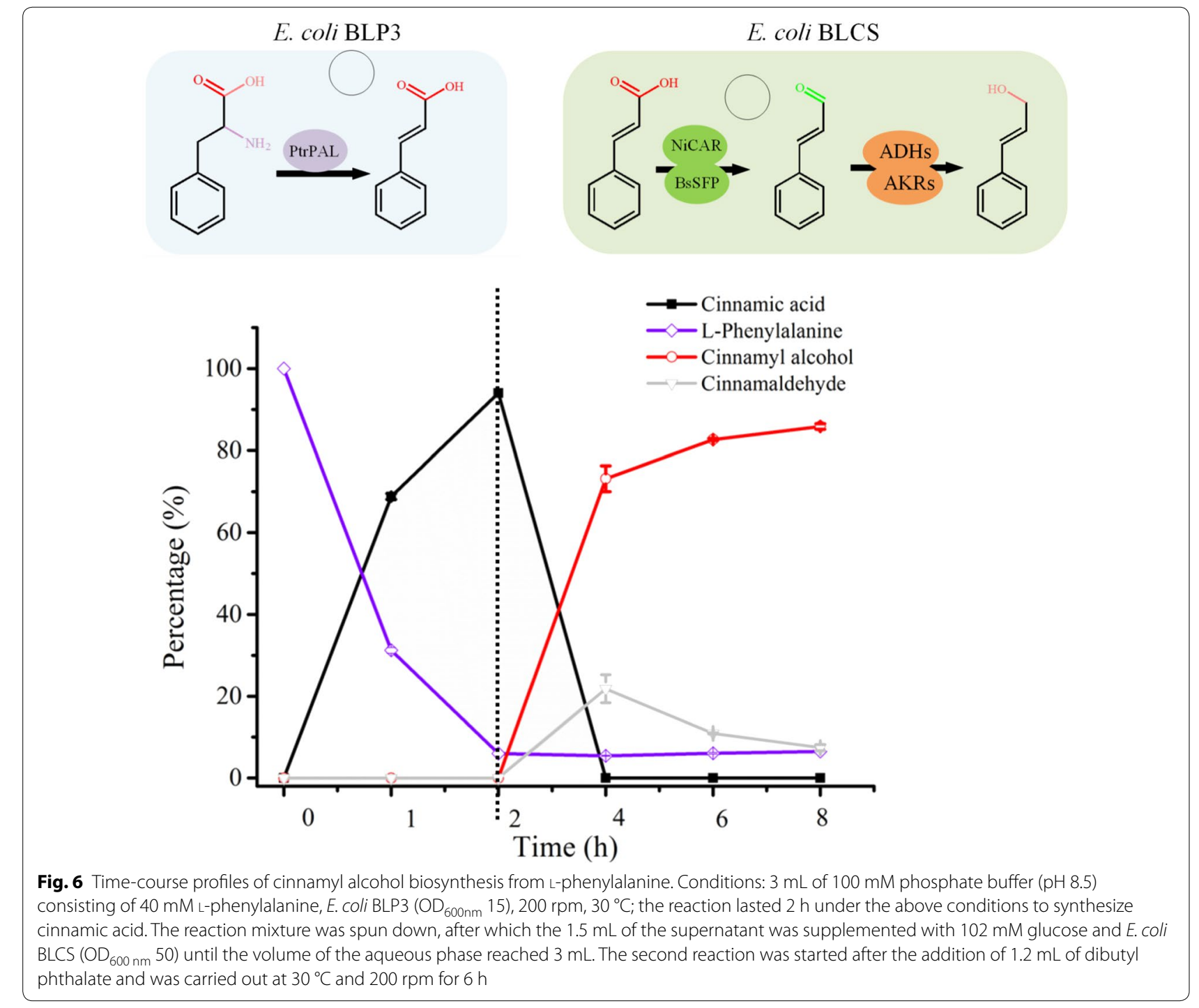


cinnamic acid was reduced to the desired product, with a yield of $88.2 \%$ in $6 \mathrm{~h}$ and the synthesized cinnamyl alcohol was concentrated to $37.36 \mathrm{mM}$ in the organic phase. Furthermore, the integration of this process with cinnamic acid production demonstrated a robust performance for cinnamyl alcohol production from L-phenylalanine. These findings open up possibilities for the practical biosynthesis of natural cinnamyl alcohol at an industrial scale.

\section{Supplementary information}

Supplementary information accompanies this paper at https://doi. org/10.1186/s12934-020-01419-9.

Additional file 1: Table S1. Strains and plasmids used in this study. Table S2. Effects of various organic solvents on the concentration of cinnamyl alcohol in the biphasic system. Table S3. The proportion of organic phase components in time-course profiles of cinnamyl alcohol biosynthesis from L-phenylalanine. Figure S1. Biosynthetic pathways from L-phenylalanine to cinnamyl alcohol. Figure S2. HPLC analysis of sample of E. coli BLCS transformation cinnamic acid after 2 h. (a) Cinnamic acid and its derivatives standard samples; (b) sample for HPLC analysis was taken at the time of $2 \mathrm{~h}$ biotransformation. Figure $\mathbf{S 3}$. Effects of temperature on whole-cell biotransformation. Figure S4. Effects of pH on whole-cell biotransformation. Figure S5. Effects of cell dosage on wholecell biotransformation. Figure S6. Effects of the ratio of cinnamic acid to glucose on whole-cell biotransformation.

\section{Acknowledgements}

We thank NRES (https://secure.authorservices.springernature.com/cn) for its linguistic assistance during the preparation of this manuscript.

\section{Authors' contributions}

$\mathrm{JO}$ and ZZ initiated and coordinated the project. CZ, QX, HH, JW performed experiments, analyzed data and wrote the paper. All authors read and approved the final manuscript.

\section{Funding}

This study was supported by National Key Research \& Development Program of China (2017YFD0600205). We also acknowledge partial support from the Priority Academic Program Development of Jiangsu Higher Education Institutions (PAPD)

\section{Availability of data and materials}

All data generated or analyzed during this study are included in this manuscript.

\section{Ethics approval and consent to participate}

Not applicable.

\section{Consent for publication}

All authors consented on the publication of this work.

\section{Competing interests}

The authors declare that they have no competing interests.

\section{Author details}

1 Jiangsu Co-Innovation Center of Efficient Processing and Utilization of Forest Resources, College of Chemical Engineering, Nanjing Forestry University, Nanjing 210037, People's Republic of China. ${ }^{2}$ Key Laboratory of Forestry Genetics \& Biotechnology (Nanjing Forestry University), Ministry of Education, Nanjing 210037, People's Republic of China. ${ }^{3}$ Jiangsu Province Key Laboratory of Green Biomass-based Fuels and Chemicals, Nanjing 210037, People's Republic of China.
Received: 28 April 2020 Accepted: 5 August 2020

Published online: 12 August 2020

\section{References}

1. Cao M, Gao M, Suastegui M, et al. Building microbial factories for the production of aromatic amino acid pathway derivatives: from commodity chemicals to plant-sourced natural products. Metab Eng. 2020;58:94-132.

2. Gottardi M, Knudsen JD, Prado L, et al. De novo biosynthesis of transcinnamic acid derivatives in Saccharomyces cerevisiae. Appl Microbiol Biotechnol. 2017;101(12):4883-93.

3. Fraaije MW, Veeger C, Van Berkel WJH. Substrate specificity of flavindependent vanillyl-alcohol oxidase from Penicillium simplicissimum: evidence for the production of 4-hydroxycinnamyl alcohols from 4-allylphenols. Eur J Biochem. 1995;234(1):271-7.

4. Gafni Y, Levy Y. Coniferyl alcohol, a lignin precursor, stimulates Rhizobiumrhizogenes A4 virulence. Curr Microbiol. 2005;50(5):262-5.

5. Savidge RA, Förster H. Coniferyl alcohol metabolism in conifers-II. Coniferyl alcohol and dihydroconiferyl alcohol biosynthesis. Phytochemistry. 2001;57(7):1095-103.

6. Rodrigo CP, James WH, Zwier TS. Single-conformation ultraviolet and infrared spectra of jet-cooled monolignols: $p$-coumaryl alcohol, coniferyl alcohol, and sinapyl alcohol. J Am Chem Soc. 2011;133(8):2632-41.

7. Tramontina R, Galman JL, Parmeggiani F, et al. Consolidated production of coniferol and other high-value aromatic alcohols directly from lignocellulosic biomass. Green Chem. 2020;22(1):144-52.

8. Özbilgin Ş, Hancı V, Ömür D, et al. Morbidity and mortality predictivity of nutritional assessment tools in the postoperative care unit. Medicine. 2016;95:40.

9. Utchariyakiat I, Surassmo S, Jaturanpinyo M, et al. Efficacy of cinnamon bark oil and cinnamaldehyde on anti-multidrug resistant Pseudomonas aeruginos a and the synergistic effects in combination with other antimicrobial agents. BMC Complement Altern Med. 2016;16:158.

10. Bang HB, Lee YH, Kim SC, Sung CK, Jeong KJ. Metabolic engineering of Escherichia coli for the production of cinnamaldehyde. Microb Cell Fact. 2016;15:16.

11. Panel TRE, Belsito D, Bickers D, et al. A toxicologic and dermatologic assessment of ionones when used as fragrance ingredients. Food Chem Toxicol. 2007;45(1):S130-67.

12. Emayavaramban B, Roy M, Sundararaju B. Iron-catalyzed allylic amination directly from alylic alcohols. Chemistry. 2016;22(12):3952-5.

13. Bonini C, Righi G. Enantio-and stereo-selective route to the taxol side chain via asymmetric epoxidation of trans-cinnamyl alcohol and subsequent expoxide ring opening. J Chem Soc Chem Commun. 1994;24:2767-8.

14. Zhou W, Bi H, Zhuang Y, et al. Production of cinnamyl alcohol glucoside from glucose in Escherichia coli. J Agric Food Chem. 2017;65(10):2129-35.

15. Chen Z, Sun X, Li Y, Yan Y, Yuan Q. Metabolic engineering of Escherichia coli for microbial synthesis of monolignols. Metab Eng. 2017:39:102-9.

16. Thévenin J, Pollet $B$, Letarnec $B$, et al. The simultaneous repression of CCR and $C A D$, two enzymes of the lignin biosynthetic pathway, results in sterility and dwarfism in Arabidopsis thaliana. Mol Plant. 2011;4(1):70-82.

17. Zhang C, Zang Y, Liu P, Zheng Z, Ouyang J. Characterization, functional analysis and application of 4-Coumarate: CoA ligase genes from Populus trichocarpa. J Biotechnol. 2019;302:92-100.

18. Klumbys E, Zebec Z, Weise NJ, Turner NJ, Scrutton NS. Bio-derived production of cinnamyl alcohol via a three step biocatalytic cascade and metabolic engineering. Green Chem. 2019;20(3):658-63.

19. Qu G, Guo J, Yang D, et al. Biocatalysis of carboxylic acid reductases: phylogenesis, catalytic mechanism and potential applications. Green Chem. 2018;20(4):777-92.

20. Finnigan W, Thomas A, Cromar H, et al. Characterization of carboxylic acid reductases as enzymes in the toolbox for synthetic chemistry. ChemCatChem. 2017;9(6):1005-17.

21. Atsumi S, Wu TY, Eckl EM, Hawkins SD, Buelter T, Liao JC. Engineering the isobutanol biosynthetic pathway in Escherichia coli by comparison of three aldehyde reductase/alcohol dehydrogenase genes. Appl Microbiol Biotechnol. 2010;85(3):651-7. 
22. Kramer L, Hankore ED, Liu Y, et al. Characterization of carboxylic acid reductases for biocatalytic synthesis of industrial chemicals. ChemBioChem. 2018;19(13):1452-60.

23. Sheppard MJ, Kunjapur AM, Wenck SJ, Prather KL. Retro-biosynthetic screening of a modular pathway design achieves selective route for microbial synthesis of 4-methyl-pentanol. Nat Commun. 2014;5:5031.

24. Napora-Wijata K, Robins K, Osorio-Lozada A, et al. Whole-cell carboxylate reduction for the synthesis of 3-hydroxytyrosol. ChemCatChem. 2014:6(4):1089-95.

25. Venkitasubramanian P, Daniels L, Das S, Lamm AS, Rosazza JP. Aldehyde oxidoreductase as a biocatalyst: reductions of vanillic acid. Enzyme Microb Technol. 2008;42(2):130-7.

26. Słomińska L, Szostek A, Grześkowiak A. Studies on enzymatic continuous production of cyclodextrins in an ultrafiltration membrane bioreactor Carbohydr Polym. 2002;50(4):423-8.

27. Arya SK, Srivastava SK. Kinetics of immobilized cyclodextrin gluconotransferase produced by Bacillus macerans ATCC 8244. Enzyme Microb Technol. 2006;39(3):507-10.

28. Bang HB, Lee $K$, Lee YJ, et al. High-level production of trans-cinnamic acid by fed-batch cultivation of Escherichia coli. Process Biochem. 2018;68:30-6.

29. Han SS, Kyeong HH, Choi JM, et al. Engineering of the conformational dynamics of an enzyme for relieving the product inhibition. ACS Catal. 2016;6(12):8440-5.

30. Laane C, Boeren S, Vox K, Weeger C. Rules for the optimization of biocatalysis in organic solvents. Biotechnol. Bioeng. 1987;30:81-7.

31. Bar R. Effect of interphase mixing on a water-organic solvent two-liquid phase microbial system: ethanol fermentation. J Chem Technol Biotechnol. 1988;43(1):49-62
32. Cruz A, Fernandes P, Cabral JMS, et al. Solvent partitioning and whole-cell sitosterol bioconversion activity in aqueous-organic two-phase systems. Enzyme Microb Technol. 2004;34(3-4):342-53.

33. Leon R, Fernandes P, Pinheiro HM, et al. Whole-cell biocatalysis in organic media. Enzyme Microb Technol. 1998;23(7-8):483-500.

34. Gong PF, Xu JH. Bio-resolution of a chiral epoxide using whole cells of Bacillus megaterium ECU1001 in a biphasic system. Enzyme Microb Technol. 2005;36(2-3):252-7.

35. Liu SP, Liu RX, Xiao MR, et al. A systems level engineered E. coli capable of efficiently producing I-phenylalanine. Process Biochem. 2014;49(5):751-7.

36. Wu WB, Guo XL, Zhang ML, Huang QG, Qi F, Huang JZ. Enhancement of I-phenylalanine production in Escherichia coli by heterologous expression of Vitreoscilla hemoglobin. Biotechnol Appl Biochem. 2018;65(3):476-83.

37. Weiner M, Albermann C, Gottlieb K, et al. Fed-batch production of I-phenylalanine from glycerol and ammonia with recombinant Escherichia coli. Biochem Eng J. 2014;83:62-9.

38. Liu Y, Xu Y, Ding D, Wen J, Zhu B, Zhang D. Genetic engineering of Escherichia coli to improve I-phenylalanine production. BMC Biotechnol. 2018;18(1):5.

39. Zhang C, Zang Y, Xu Q, et al. Comparison on activities of phenylalanine ammonia-lyase from Populus trichocarpa and its application in trans-cinnamic acid production. J Nanjing Forestry Univ (Nat Sci Ed). 2020;44(1):97-104.

\section{Publisher's Note}

Springer Nature remains neutral with regard to jurisdictional claims in published maps and institutional affiliations.
Ready to submit your research? Choose BMC and benefit from:

- fast, convenient online submission

- thorough peer review by experienced researchers in your field

- rapid publication on acceptance

- support for research data, including large and complex data types

- gold Open Access which fosters wider collaboration and increased citations

- maximum visibility for your research: over $100 \mathrm{M}$ website views per year

At BMC, research is always in progress.

Learn more biomedcentral.com/submissions 